\title{
ENERGIA SOLAR FOTOVOLTAICA: REVISÃO BIBLIOGRAFICA
}

\author{
Thiago Rocha Lana(FIC/UNIS) - Thiago.lana@alunos.unis.edu.br \\ José Antônio Silva Júnior (FIC/UNIS) - jose.junior1@alunos.unis.edu.br \\ Matheus Segundo da Silva(FIC/UNIS) - matheus.silva9@alunos.unis.edu.br \\ Matheus G. Talarico(FIC/UNIS) - matheus.talarico@alunos.unis.edu.br \\ Tiago Bittencourt Nazare - tiago@unis.edu.br
}

\section{RESUMO}

A demanda pela diversificação da matriz energética brasileira tem se tornado cada vez mais importante, sendo estimulado por dois principais fatores. Primeiro pelo atual panorama energético, pois a diminuição das chuvas vem acontecendo frequentemente e a consequência faz com que aconteça a redução de energia geradas pelas hidrelétricas. E ainda, pela necessidade de explorar recursos renováveis que trazem flexibilidade e sustentabilidade quando da sua utilização.Diante deste cenário, a energia solar fotovoltaica apresenta-se como uma tecnologia em constante avanço, no Brasil e no mundo. O trabalho busca apresentar o princípio de utilização da energia, demostrando sua metodologia e seus impactos no cenário mundial. Com base em pesquisas realizadas, artigos e revistas, tem-se uma visão da utilização da luz solar para a produção de energia elétrica através de painéis fotovoltaicos, sendo aplicada em casas, iluminações públicas, fábricas e etc.

Palavras-chave: Energia elétrica. Luz solar. Fotovoltaica.

\section{Abstract}

The demand for diversification of the Brazilian energy matrix has become increasingly important, being stimulated by two main factors. First, due to the current energy scenario, since the decrease in rainfall has been happening frequently and the consequence causes the reduction of energy generated by hydroelectric plants. And yet, due to the need to explore renewable resources that bring flexibility and sustainability when used. Faced with this scenario, photovoltaic solar energy presents itself as a technology in constant advance, in Brazil and in the world. The work seeks to present the principle of energy use, considering the equipment and materials applied to the system, as well as the efficiency involved. At the end, there is an expanded view of the use of sunlight for the production of electric energy through photovoltaic panels, being applied in houses, public lighting, factories, etc.

Keywords: Electric energy. Sun light. Photovoltaic. 


\section{INTRODUÇÃO}

A muito anos atrás, a humanidade vem utilizando todos os recursos naturais que estão presente no planeta, para suprir suas necessidades energéticas, sem se preocupar com os efeitos que causariam ao meio ambiente.

De acordo com Gore (2014, p.32), "a civilização humana e o ecossistema terrestre estão entrando em choque, e a crise climática é a manifestação mais proeminente, destrutiva e ameaçadora desse embate". A atual situação climática brasileira ilustra o apresentado pelo autor, já que o comportamento do tempo não está de acordo com os parâmetros já estudados das estações climáticas do ano.

As pesquisas e investimentos em tecnologias voltadas para área energética vem se tornado cada vez mais eficiente sua procura, pois a diversificação da matriz energética tem aumentado cada vez mais. Com isso, a energia solar fotovoltaica tornou-se mais conhecida e ampliou seu mercado econômico e acadêmico.

O grande potencial solar energético do Brasil vem se tornando cada vez mais comum, e o artigo aborda algumas questões relacionadas a utilização da energia solar, e apresenta uma grande evolução que vem se tornando importante no mundo moderno. Por consequência foi feito um estudo sobre a utilização de energia fotovoltaica.

A energia solar vem ganhando cada vez mais força na matriz elétrica brasileira. Além de possuir mais vantagens que outras fontes tradicionais de energia elétrica, como carvão e gás. A redução dos custos de implantação em projetos solares faz com que a energia solar se torne a forma menos custosa na produção de eletricidade. Esse modelo de geração de energia, produzida através do uso do sol, é considerada inesgotável do ponto de vista humano, trazendo um potencial extraordinário comparado com outras fontes de energia

A finalidade da energia fotovoltaica é levar energia em locais de difícil acesso ou em lugares com dificuldades para instalação de torres e de cabos elétricos. E transformar a energia solar em energia elétrica sendo assim uma fonte de energia limpa, pois não transmite gases nocivos ao meio ambiente. 


\section{METODOLOGIA}

Na elaboração desse artigo foram pesquisados diversos artigos sobre esse assunto, e usamos a plataforma Google Acadêmico, com ênfases em artigos relacionados a produção de energia fotovoltaica ou energia solar. As pesquisas foram realizadas entre os meses de Maio a Julho de 2020 e com atualizações em Setembro de 2020.

Foram reunidas todas as informações de pesquisas para que pudessem ser organizadas e deixar o artigo mais explicado e detalhado, realizou um planejamento para verificar quais conteúdos seriam abordados e onde iria coletar as informações sobre o assunto. Por fim, as informações coletadas, organizadas e estudas foram redigidas no artigo.

\section{FUNCIOMAMENTO DO SISTEMA DE ENERGIA SOLAR}

No início foram criadas as células fotovoltaicas, porem teve uma grande preocupação pois apresentava um alto custo o que tornava inviável. Então começaram a baixar o custo na fabricação das células na década de 90 pois ocorreu um grande avanço na produção de energia através do sistema fotovoltaico. Como no século XXI teve um aumento na geração de energia solar, a tecnologia vem avançando cada dia mais e também uma buscar de energia limpa para não causar grandes impactos ambientais no meio ambiente.

O funcionamento do sistema de energia fotovoltaica, é mais conhecido como sistema de energia solar. É um sistema que realiza a produção de energia elétrica através da radiação solar. Esse sistema consegue fazer com que o próprio consumidor de energia elétrica consiga gerar sua própria energia, e isso ocorre através da sua capacidade de captação de energia solar é obtida através da conversão da radiação solar em energia elétrica, por intervenção de placas feita com materiais semicondutores, como por exemplo o silício.

Segundo Nascimento (2004) o efeito fotovoltaico ocorre através das matérias semicondutores que fazem a conversão direta da luz solar em eletricidade esse fenômeno foi descoberto em 1839 por Edmond Bacquerel, quando no extremo de uma estrutura feita com materiais semicondutores, surgiu uma diferença de potencial elétrico. O efeito fotovoltaico corresponde a uma geração de diferença de potencial elétrica em dois terminais. 
O elemento principal é a célula pois seu objetivo é captar a luz solar e converter a energia em corrente continua no sistema fotovoltaico, as células mais usadas no mercado e fabricadas é através do silício,cada uma gera uma tensão elétrica e associando elas em série ou paralelo conseguimos os valores desejados e assim tem o nome de painel solar. Mas para a energia chegar em perfeito estados ela passa por um inversor que tem como finalidade transformar a corrente continua em corrente alternada e assim sendo distribuída para o local que será usada, como indústria, residência ou para outros fins. E existe também um relógio que tem como objetivo controlar a entrada e retorno de energia do local onde instalado.

E quando a energia volta para concessionaria ela é emprestada e assim o consumidor é ressarcido por créditos energéticos, assim o consumidor possui um credito valido a 5 anos, sendo assim utilizado para abater no que ele consumiu da rede. Desta forma o consumidor poderá reduzir em sua conta de luz em aproximadamente $95 \%$.

Figura 1: Funcionamento da instalação do sistema fotovoltaico na residência.

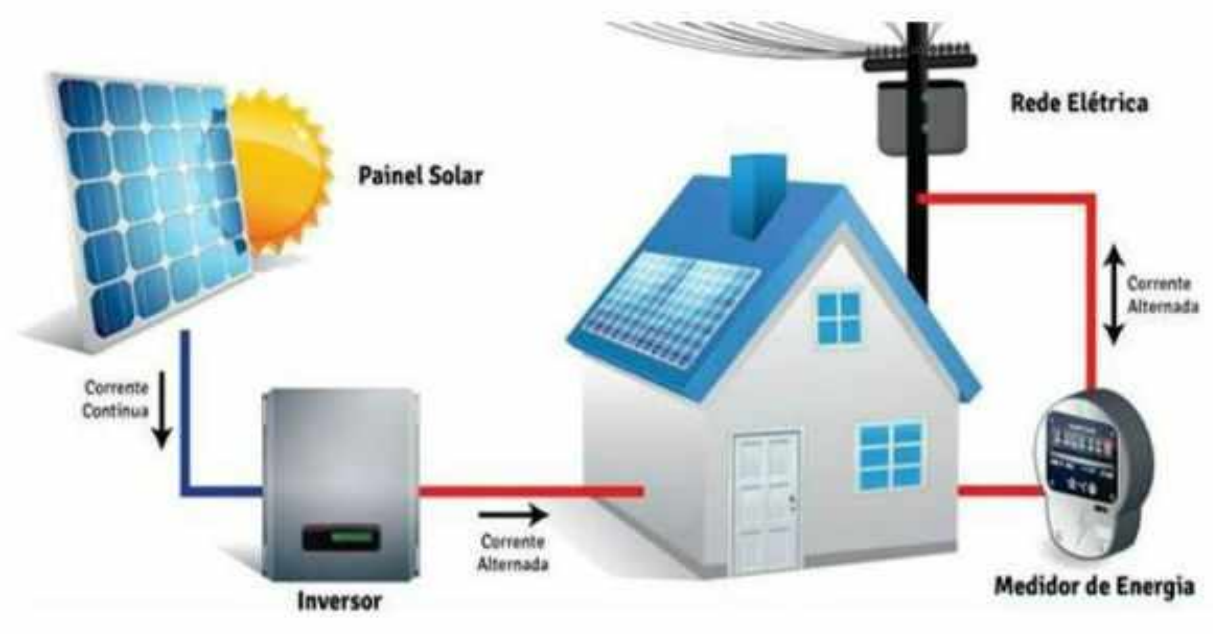

Fonte : Danilo Candido Cunha; Energia solar fotovoltaica no Brasil - 2020

\section{ENERGIA FOTOVOLTAICA NO CENÁRIO INTERNACIONAL}

Segundo o site Blue Sol (2020) a empresa de inteligência de negócios IHS Markitem seu relatório "Previsão da demanda fotovoltaica global para 2020", estima novos 142 Gigawatts 
(GW) de energia solar este ano.O volume representa um crescimento de $14 \%$ em relação a capacidade instalada em 2019 e uma grande evolução frente ao começo da década passada, quando eram $20 \mathrm{GW}$ instalados.

De acordo com as previsões da $\boldsymbol{I H S}, 43$ países deverão atingir capacidades instaladas acima do $1 \mathrm{GW}$ este ano. Em 2010 eram apenas 7. Umas das mais expressivas fontes de energia renovável no Brasil, a solar fotovoltaica registra capacidade instalada de 4,4 GW no país hoje, entre geração centralizada e distribuída.

A china é o maior mercado fotovoltaico do mundo e devera novamente liderar a expansão de energia solar em 2020. E nos EUA a energia solar deve crescer em torno dos $20 \%$ e consolidar o segundo maior mercado do mundo. Entre os estados americanos de destaque estão Califórnia, Texas, Flórida, Carolina do Norte e Nova York. Enquanto na Europa as instalações fotovoltaicas deverão crescer mais de $24 \mathrm{GW}$ este ano, 5\% a mais que em 2019. E novos mercados irão surgir na América Latina, Oriente Médio e Sudeste asiático nesta década.

Segundo site Portal Solar (2020) a única fonte que irá apresentar crescimento em 2020, aponta relatório da Agência Internacional de Energia (IEA) que avalia os impactos da pandemia de corona vírus e as consequentes medidas de restrição na demanda e oferta global do setor. De acordo com a análise, esse tipo de geração, em especial solar deve superar os problemas de cadeia de suprimentos e apresentar um incremento de cerca de 5\% em 2020.

O diretor executivo da IEA, Faith Birol, disse que; "Em meio a essa crise econômica e sanitária sem precedentes, a queda de demanda de quase todos os principais combustíveis é impressionante, especialmente para carvão, petróleo e gás. Apenas as renováveis irão se sustentar durante essa queda no uso de eletricidade".

As economias mais avançadas sofreram o maior impacto. A IEA prevê que a demanda de energia nos Estados Unidos caia 9\% e 11\% na União Europeia em 2020, em função dos efeitos de restrição na atividade industrial. O papel das renováveis na matriz energética dos dois mercados já mostra crescimento.

A energia solar tende a crescer cada vez mais em todo o mundo, por ser uma fonte de energia limpa, sem causar grandes impactos ambientais, e cada ano que se passa ela vem barateando cada vez mais.

\section{POTENCIAL EM ENERGIA SOLAR NO BRASIL}


A crescente preocupação com a preservação do meio ambiente, e a busca peladiversificação da matriz elétrica, associado com o aumento na demanda por energia,desenvolvimento da indústria e a redução dos custos de tecnologias, impulsionaram ageração de energia elétrica no mundo a partir de fontes renováveis, como a fonte solar, bemcomo uma transição para os sistemas distribuídos de energia (DJØRUP; THELLUFSEN;

SORKNÆS, 2018; SCHLEICHER-TAPPESER, 2012). As fontes renováveis,principalmente a solar, vem se destacando nos últimos anos com o crescimento da geração distribuída. As fontesrenováveis tornaram-se mais competitivas na medida em que se desenvolveram, sendo acompetitividade resultante da redução dos custos devido aos avanços tecnológicos.

O Brasil é um país que possui um dos maiores potenciais para geração de energia fotovoltaica no mundo, como mostrado na Figura 2.1, contando com níveis de irradiação solar superioresaos de países onde projetos para aproveitamento de energia solar são muito mais avançados,como Alemanha, França e Itália, segundo o INPE(2017).

O INPE (2017) afirma também que a região Nordeste é a região queapresenta o maior potencial solar no Brasil, com valor médio do total diário da irradiaçãoglobal horizontal de $5,49 \mathrm{kWh} / \mathrm{m}^{2}$ e da componente direta normal de $5,05 \mathrm{kWh} / \mathrm{m}^{2}$. A Figura

2.2 compara a variabilidade da irradiação global horizontal média mensal nas cinco regiõesbrasileiras com os países citados anteriormente.

Figura 2.1. Total diário da irradiação brasileira no plano inclinado na latitude. 


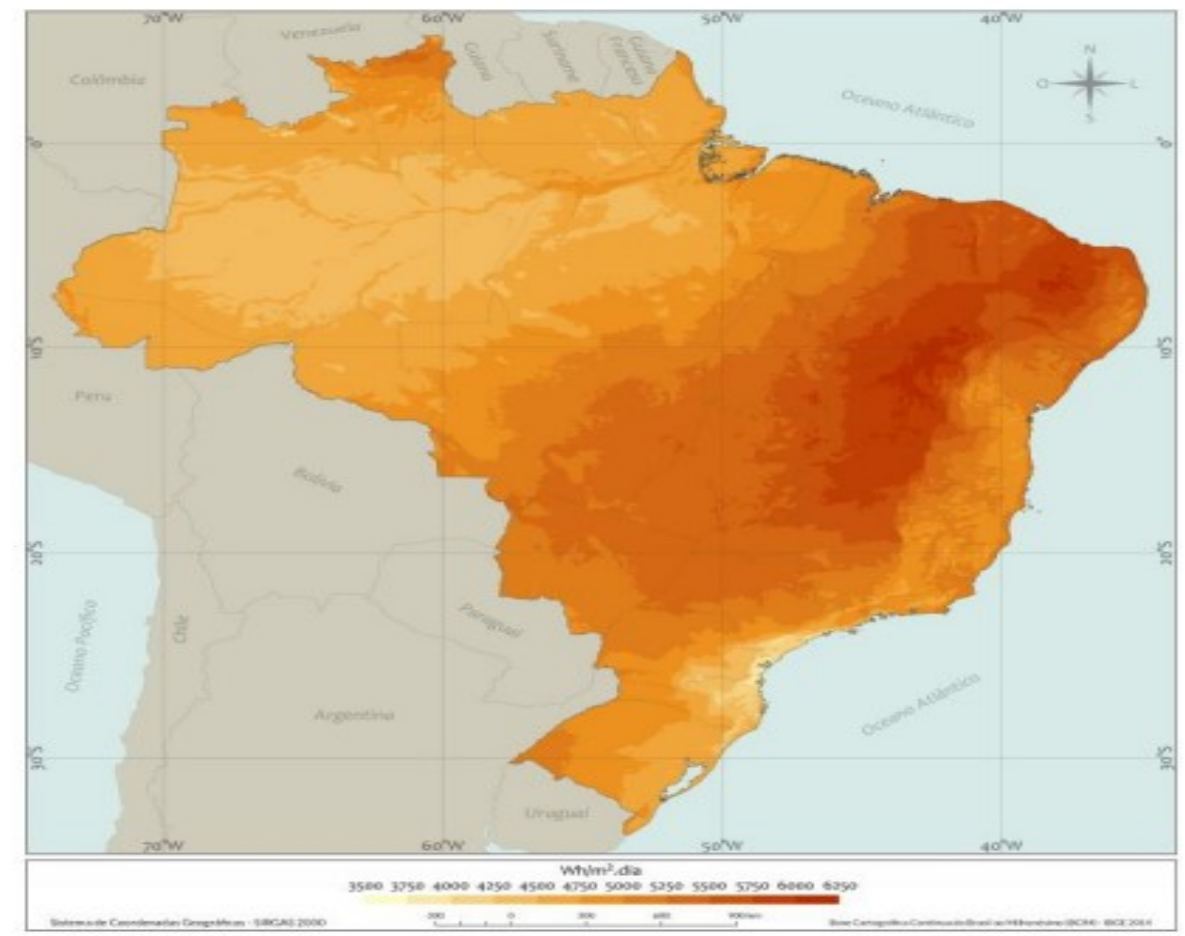

Fonte: INPE (2017)

Figura 2.2. Comparativo das médias mensais da irradiação global horizontal no Brasil e alguns países da Europa $\left(\mathrm{kWh} / \mathrm{m}^{2}\right.$. dia)

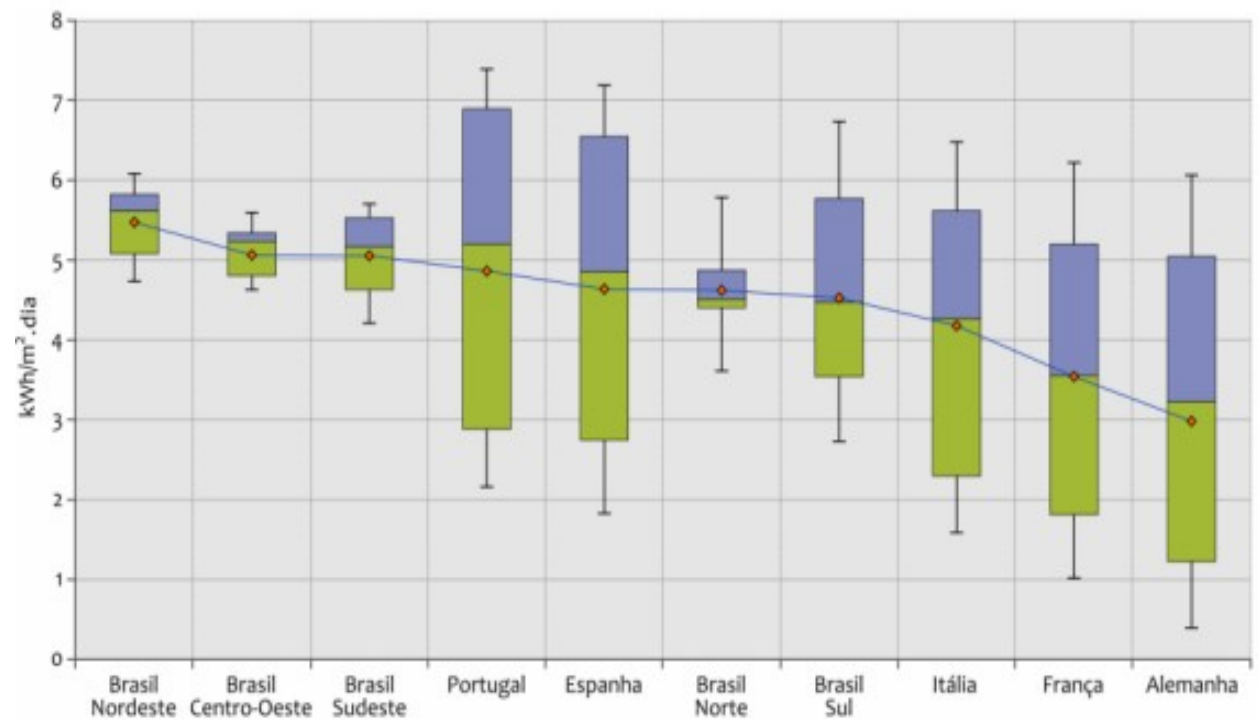

Fonte: INPE(2017)

\section{CRESCIMENTO DE ENERGIA SOLAR NO CENÁRIO NACIONAL}

Segundo o site Portal Solar (2020), os paísesEstados Unidos, Japão, Alemanha e China estão na liderança da lista mundial de países com maior potencial instalado de energia 
fotovoltaica.Para quem já está familiarizado com tais países, sabe que é muito comum encontrar pelas ruas das cidades painéis instalados na maioria das residências. Essa produção da própria energia, espalhou-se também por toda quase todo continente Europeu, tendo em vista as vantagens em se utilizar tal energia.

Segundo a revista Núcleo do Conhecimento (2018), o Brasil, antes de 2012, não possuía regulamentação para produção de energia solar, por isso ficava muito atrás desses países desenvolvidos. Em 2012, 17 de abril para ser mais exato, foi permitido o acesso de micro geração e mini geração aos sistemas de energia elétrica nacional (rede elétrica das concessionárias), através das normas criadas na resolução 482 da ANEEL (agencia nacional de energia elétrica), fazendo com que todo consumidor cadastrado com CPF ou CNPJ, ativo, tem liberdade para conectar seu próprio sistema de geração de energia, vindo das fontes renováveis, paralelamente as redes de distribuição das concessionárias.

Segundo site da ANEEL (2018), devido a essa liberação de energias renováveis para consumidores ativos, o Brasil tendo um crescimento espantoso com o número de sistemas instalados. Em 2012 eram apenas 7 sistemas solares instalados, segundo os dados da Agência Nacional de Energia Elétrica (ANEEL), foram 110.997 sistemas instalados no ano em todo o país, entre mini e micro geradores. Em 2018, o total foi de 35.540. E para 2020, a previsão é que chegue a marca de 174 mil painéis solares instalados. Estima-se que, em 2024, haverá, aproximadamente, 887 mil sistemas de energia solar conectados à rede no território brasileiro.

Figura 3: Projeção de MW no país de painéis solares.

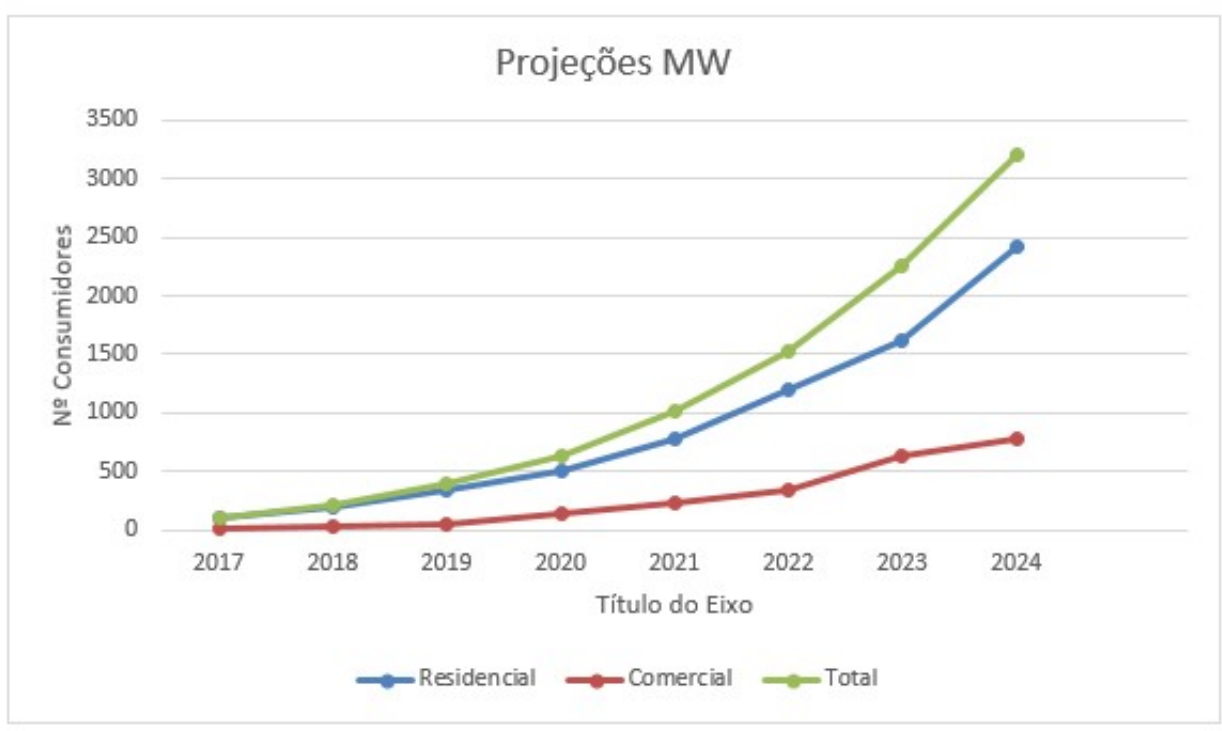


Fonte: Adaptado pelo autor com base no relatório do IV Congresso Brasileiro de Energia Solar e na Conferência Latino-Americana da ISES - São Paulo, 18 a 21 de setembro de 2018.

\section{VANTAGENS E DESVANTAGENS DO SISTEMA FOTOVOLTAICA}

A energia fotovoltaica utiliza como fonte energética para a produção de eletricidade, a luz solar. Tem como principais vantagens ser uma fonte de energia limpa, gratuita e renovável, trazendo benefícios ambientais, econômicos e sociais. Entre as suas desvantagens, está a falta de produção durante o período noturno, onde não há luz solar.

Esse sistema energético tem também, como benefício, seu simples modo de instalação, gerando uma economia de até $95 \%$ em sua conta de luz. É um sistema que ocupa muito pouco espaço, facilitando demais sua implantação em diferentes áreas, tanto urbanas quanto áreas rurais, e também uma alternativa para lugares onde ainda não há distribuição de energia elétrica por meio das concessionárias.

É uma energia 100\% renovável, onde a luz do sol é uma fonte de energia constante. Dos recursos renováveis como energia eólica, hídrica e solar, ela é a mais consistente e previsível.

Seu sistema de funcionamento não oferece nenhum ruído, ou seja, não há poluição sonora. É uma energia que não polui o meio ambiente. Praticamente não precisa de manutenção, seus painéis duram em média 25 anos apenas com limpezas anuais. Se olharmos bem, ela é uma energia com um ótimo custo benefício, considerando o tempo de vida útil de seu painel, pela quantidade de energia elétrica produzida, fazendo com que os custos das contas de luz sejam nitidamente mais baixos durante os anos de uso.

Segundo o Laboratório Nacional Lawrence Berkeley (EUA), com a implantação do sistema fotovoltaico, o valor do imóvel pode crescer de 4\% a 6\%. Já em casos de imóveis sustentáveis certificados, esse número pode aumentar para 30\%, segundo a revista STAND, em 2014.

ANEEL (2018), através do Relatório de Análise de Impacto Regulatório n ${ }^{0}$ 0004/2018SRD/SCG/SMA/ANEEL, pontuou os seguintes benefícios: "Redução de perdas nadistribuição; Redução de perdas na transmissão; Energia evitada (kWh); Expansão degeração evitada $(\mathrm{kW})$; Redução na emissão de gás de efeito estufa; Geração de emprego”.

Para Rodrigo Sauaia, da Associação Brasileira de Energia Solar Fotovoltaica - ABSOLAR,a Geração Distribuída fotovoltaica traz diversos benefícios para o Brasil (SAUAIA, 2019), conforme mostrado noQuadro 2.1. 
Quadro 2.1. Benefícios da GDFV no Brasil.

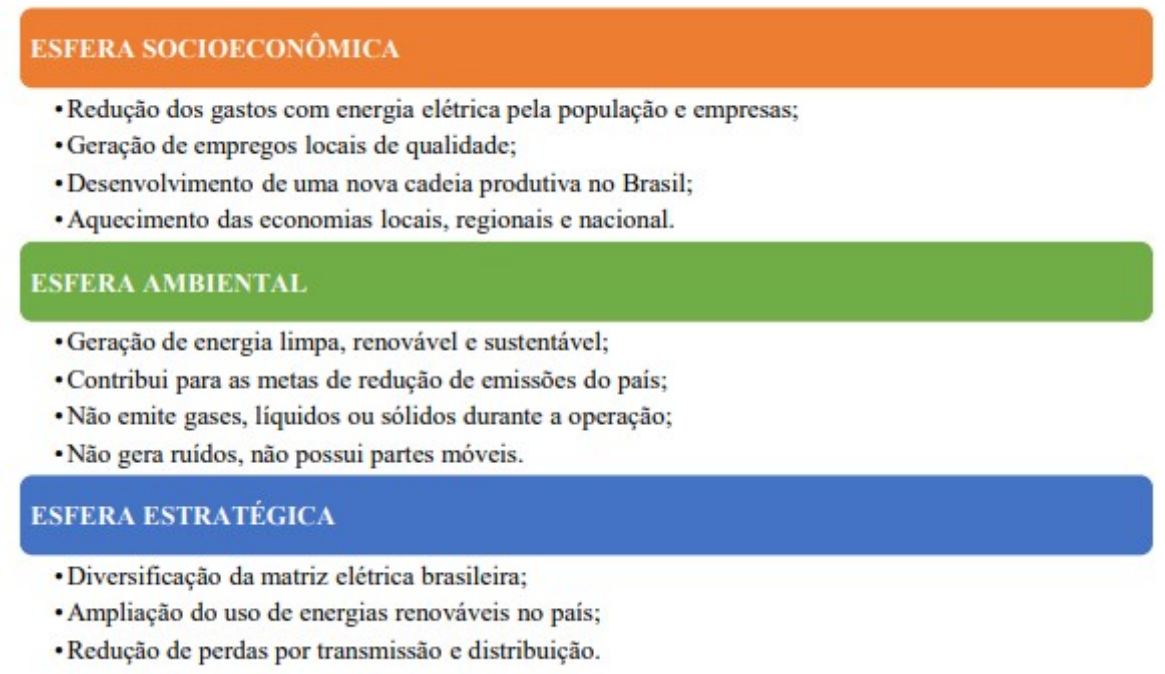

Fonte: Adaptado de Sauaia(2019)

Já suas principais desvantagens, que são poucas, se prendem muito ao fato do sistema fotovoltaico não funcionar durante o período da noite. Seu alto custo de implantação, de imediato, também pode ser um problema, devido as células solares e painéis solares serem de um custo mais elevado, porém esse fato se desfaz quando vemos seu custo em relação a sua durabilidade e economia.

Outra desvantagem também, para o povo brasileiro, é a falta de incentivo fiscal do governo, fazendo com que essa solução pareça pouco acessível. Existem também algumas linhas de financiamento desses sistemas, porem os juros abusivos fazem disso outro empecilho para implantação.

\section{CONSIDERAÇÕES FINAIS}

Dadas as informações do artigo, chegamos ao nosso objetivo que era apresentar o conceito da energia fotovoltaica, seu funcionamento, equipamentos e suas expansão no território nacional e internacional. Os resultados foram atingidos através de pesquisas realizadas em artigos, revistas e sites conceituados, onde demostramos nas referências bibliográficas.

Fica ainda necessário, lembrar que a Energia Fotovoltaica não é apenas uma solução viável a sustentabilidade do país, mas sim uma forma nova de produção de riqueza e conhecimento 
aoBrasil, podendo ser responsável de livrá-lo de contas caras e custos altos para fornecimento de energia e podermos usufruir de uma fonte de energia limpa.

\section{REFERÊNCIAS BIBLIOGRÁFICAS}

CEPEL - CENTRO DE PESQUISAS DE ENERGIA ELÉTRICA. A energia solar no Brasil. 2013.

MACHADO, C.; MIRANDA, F. Energia Solar Fotovoltaica: Uma breve revisão. Outubro 2016.

ANEEL - AGÊNCIA NACIONAL DE ENERGIA ELÉTRICA. Relatório Aneel 2013. Acesso 2020.

Potencial de Energia Solar. Disponível em: $<$ http://www.greenpeace.org/brasil $>$. Acesso em 2020 .

Ministério de Minas e Energia, Nota Técnica 19/14 - Inserção da Geração Fotovoltaica Distribuída no Brasil, do Ministério de Minas e Energia. Disponível em: $<$ http://www.mme.gov.br>. Acesso em: 2020.

GORE, A. Nossa escolha: um plano para solucionar a crise climática. Our choice: a planto solve the climate crisis. Barueri, SP: Manole, 2014.

PINHO, J.; GALDINO, M. Manual de engenharia para sistemas fotovoltaicos. Rio deJaneiro: Cepel-Cresesb, 2014.

SOLAR ENERGY INTERNATIONAL. Photovoltaics Design and Installation Manual.Canadá: New Society Publishers, 2004. 